\title{
ARE WE DOING ENOUGH IN PROMOTING BREAST CANCER SCREENING: AN EVALUATION OF MALAYSIA BREAST CANCER SCREENING PROGRAM
}

\author{
Zakiah Mohd Said ${ }^{1,2}$ and Rosnah Sutan ${ }^{1}$ \\ ${ }^{1}$ Community Health Department, Medical Faculty, University Kebangsaan Malaysia,Jln Yaakob Latif Bandar Tun Razak, \\ 56000 Cheras Kuala Lumpur, Malaysia \\ ${ }^{2}$ Family Health Development Division, Ministry of Health, Precint 1, Wilayah Persekutuan Putrajaya, Malaysia
}

Corresponding author: Rosnah Sutan

Email: rosnah.sutan@yahoo.com OR rosnah.sutan@ppukm.ukm.edu.my

\begin{abstract}
Breast cancer is the most common cancer affecting women globally. Several ways of breast cancer screening tools are available. This study aims to evaluate Malaysia's breast cancer screening program using the national database based on participation and performance indicators for the past five years. A retrospective cumulative analysis of clinical breast examination and mammogram screening services were performed using the national dataset of 2016-2020 obtained from the Health Informatics Centres, Ministry of Health Malaysia. The performance indicator represents the percentage of breast abnormality detected during clinical breast examination and the proportion of confirmed cancer through mammogram screening. A reduction in the participation rate for clinical breast examination was noted from 2016 (25.8\%) to 2020(25.1\%). However, a high participation rate in 2019 (29.1\%) was noted following active health promotion intervention. The rate of high-risk women who underwent mammogram screening fluctuated by years according to active breast awareness campaign. The average rate of confirmed breast cancer annually was $0.7 \%$ and was noted highest in 2020 (1.17\%). Improving early diagnosis is an eminent strategy for cancer control in all settings, including strengthening health systems and providing universal health coverage. Successful breast cancer prevention and control programs require intersectoral planning and active community participation. Ensuring sustainability and accessibility of breast cancer screening programs is highly needed. Fostering good collaborative multiagency partnership and community participation for the cancer control program urges an innovative approach through a policy formulation.
\end{abstract}

KEYWORDS:breast cancer, screening, policy, empowerment

\section{INTRODUCTION}

Breast cancer is the most common cancer in women worldwide, accounting for $24.2 \%$ of all new cancer cases detected with the agestandardized rate (ASR) 46.3 per 100,000 population and $15 \%$ of cancer deaths in $2018^{1}$. Incidence for women breast cancer accounts for one in fourth cancer cases and one in sixth cancer deaths, making it the most significant disease burden in most countries ${ }^{2}$. Even though the incidence of breast cancer rises at all ages in high-income countries, women in lower-income countries have a more significant risk of breast cancer mortality, particularly women under the age of 50 years old ${ }^{3}$. Women are generally presented at an advanced stage of illness of stage III or stage IV in developing countries ${ }^{4}$.

Malaysia is a country in South East Asia with an upper-middle income, likewise sees the same trend. Breast cancer is the most common cancer, accounting for $19 \%$ of all malignancies and 34.1 per cent of all cancers in women in Malaysia ${ }^{5}$. The ASR has increased from 31.1 per 100,000 population (2007-2011) to 34.1 per 100,000 populations $(2012-2016)^{5}$. The incidence began to rise at the age of 25 and peaked between 60 and 64 years old. The Chinese ethnicity was the most affected, with a rate of 40.7 per 100,000 , followed by Indians (38.1 per 100,000) and Malays
$(31.5 \text { per } 100,000)^{5}$. At the time of diagnosis, the majority of cases were detected at an advanced stage (III and IV), which was higher cases detected in the year 2012-2016 (47.9\%) compared to $2007-2011(43.2 \%)^{5}$. Delayed presentation remains very common problem among breast cancer patients due to several determinant factors. These factors include structural inadequacies, social impediments such as a strong belief in traditional medicine and has a negative perception of the disease, personal beliefs, and financial hindrance in assessing health services ${ }^{6}$. The advantages of breast cancer screening and early detection, such as reduced morbidity and mortality, have been proven in multiple studies ${ }^{7}$. It has been suggested that screening could increase breast cancer incidence by $30 \%$ when organized programs are available and at an affordable cost ${ }^{8}$. An estimate of 85 per cent or more of the target population reduces mortality by 40 per cent ${ }^{9}$. Breast self-examination (BSE), clinical breast examination (CBE), and mammography (MMG) screening are all options for detecting abnormalities in the breast. Breast selfexamination (BSE) and clinical breast examination (CBE) have long been considered imperative for implementation at the population level. Randomized studies in China ${ }^{10}$ and Russia have not supported BSE as an early detection technique ${ }^{11}$. Although CBE continues to be part of the examination of symptomatic women, there is 
little evidence for screening asymptomatic women using CBE alone or combined with a mammogram $^{12}$. Because of the lack of documented benefits and the possibility of falsepositive results, the American Cancer Society (ACS) discourages CBE in middle-risk women of any age group ${ }^{13}$.

On the other hand, a prospective randomized controlled trial was conducted on 151,538 women who were followed up for 20 years in India. It was discovered that biennial CBE had downstaged breast cancer and reduced mortality significantly among women aged 50 years and above ${ }^{14}$. According to the World Health Organization, CBE as a stand-alone screening approach could be a low-cost option in low-resource regions where health systems are weak. However, more evidence is required before formulating policy ${ }^{15}$. Malaysia currently practices opportunistic breast cancer screening program implemented in all primary healthcare fascilities. The current breast cancer screening policy recommended by the Ministry of Health Malaysia includes encouraging breast self-examination(BSE) in all women as part of a breast cancer awareness program ${ }^{16}$. The clinical breast examination (CBE) is offer to all young women aged 20 to 39 years old and also to older women (40 years old and above) attended the clinic or any breast cancer awareness campaign. Every three years, they are encouraged to have a clinical breast examination by a competent health care professional 16 . Older women and those at higher risk for breast cancer are encourage to get a clinical breast examination every year, regardless of age ${ }^{16}$.

According to the existing Clinical Practice Guidelines for the Management of Breast Cancer, women identified as high risk will be managed accordingly depending on their age and other factors ${ }^{17}$. Women who were screened positive by CBE are referred to the appropriate facility for diagnostic mammography and other management investigations. Since 2012, a targeted mammography screening program has been available to vulnerable women facing higher risk for breast cancer. Women with BRCA (breast cancer genetic) and first-degree relatives of BRCA carriers enormously increased the risk of having breast cancer. Other histories of chest irradiation at a younger age and a strong family history of breast or ovarian cancer have been linked to breast or ovarian cancer risk ${ }^{17}$. The primary care clinics provide an entry point for high-risk women before being referred to mammography services in government hospitals or private hospitals.

As far as access is concerned, there are many ways for a woman to obtain mammography assessment. A subsidized program by the National Population and Family Development Board (NPFDB) and Social Security Organization (SOCSO) were amongst other optional providers. Depending on their income, women would be screened for free or with minimal price of RM50. Women with household income RM 10,000 and above will benefit from a subsidy of RM 50 for a mammogram by NPFDB. Workers aged 40 years and above who have contributed to SOCSO will be entitled to medical screening with additional mammogram vouchers for female employees ${ }^{16}$. Nevertheless, some of the state governments are also providing the services in their respective states. It is based on the subsidized ratio or free of charge. The criteria depend on the households income of the family. Apart from that, a woman may choose private hospitals, non-governmental organizations or pay out-of-pocket for it. As the program has reached almost a decade, there is a need to evaluate the program as a whole. This paper highlights the essential performance findings of the program with regards to the participation and performance indicators for the past five years. It helps to facilitate the improvement of the breast cancer screening policy. Developing effective policies to detect cancer early can save lives and reduce cancer care's personal, societal, and economic costs.

\section{METHODS}

The present study used secondary 2016-2020 merged data obtained from the National Health Informatics Centres. This centre is responsible for collating all the data from various breast cancer screening providers within the Ministry of Health. It will allow each level of services provider in the primary healthcare clinics, district health office, and state health department to upload, submit data and view the aggregated report of all family health programs, including the breast cancer screening and prevention program. The National Health Management Information System generated a standard excel spreadsheet analysis from the system to produce a report of the output/outcome of the program. Data analysis for the present study used the performances of clinical breast examination and mammogram screening services.

All women who came or were referred for clinical breast examination and mammogram were registered in the standard registration book in the primary care clinic. The information in the book was transferred to the reporting format using the standard reporting excel spreadsheet for analysis. The data was based on three reports submitted quarterly, which are the clinical breast examination achievement report (PKW 206 format), mammogram screening services for highrisk women (PKW 207 format), and providers for mammogram screening services (PKW 208 format).

\section{Data collection}

Variable studies are based on process and performance indicators. The process indicator measured the participation rate for clinical breast examination and the high-risk women who 
underwent mammogram screening. The performance indicator represents the percentage of breast abnormality detected during clinical breast examination and the proportion of confirmed cancer through mammogram screening. The clinical breast examination coverage can be represented by the clinical breast examination's participation rate, defined as the number of women screened by the health care provider divided by the target population, women aged 20 and above. The denominator will be verified and distributed by the Department of Statistics Malaysia. It has been set at least $25 \%$ of women aged 20 years and above need to be screened through clinical breast examination ${ }^{18}$. It is a national target that requires continuous monitoring at the district, state, and national levels. The percentage of breast abnormality detected during clinical breast examination is defined as the total number of breast abnormalities detected through clinical breast examination divided by the total number of women who underwent clinical breast examination. Once detected, the patient will be referred to the surgical team in secondary/tertiary care for further assessment. CBE was considered abnormal in the presence of palpable mass, discharge from the nipple, retraction of the skin or nipple, oedema, erythema or skin ulcers. The mammography rate is defined as the total number of women screened by mammography divided by eligible women registered. The proportion of confirmed cancer is defined as the total number of high-risk women who underwent mammogram screening and confirmed the cancer was divided by the number of women who went for mammogram screening. The collected data were analyzed using an excel spreadsheet and presented descriptively.

\section{RESULTS}

Table 1 shows the summary of performance indicators of early detection and screening breast cancer programs in Malaysia. During 2016-2020, a total of 8,030,002 women underwent clinical breast examination in primary health clinics. The rate ranged from $25.0 \%$ to $29.2 \%$, and the average rate was $26.6 \%$. It was noted that the lowest rates occurred both in 2018 and 2020 . From this analysis, 18,466 out of $8,030,002(0.2 \%)$ were found to have abnormal findings of the clinical breast examination. The abnormal findings can be categorized as a breast lump, skin discolouration, abnormal breast texture, abnormality of the nipple, abnormal discharge from the nipple, and continuous breast pain. However, there was no detail of the specific findings in the analysis ${ }^{16}$.

Concerning high-risk groups taking part in mammography screening, 120,228 women were registered between 2016 to 2020 . Overall, $61.0 \%$ $(72,993)$ of women registered in 2016-2020 have undergone mammography, with an average rate of $0.7 \%$ ( 534 women) were confirmed cancer per year. Figure 1 to Figure 6 show the detail analysis of the achievement of each screening method. Figure 1 shows the participation rate of clinical breast examination by age category. It shows that more than $75 \%$ of women who participated were in the age range of 20-39 years old. These women were in the reproductive stage, who came to the primary care clinic for antenatal, post-natal check-ups, and family planning services.

Table 1: Performance indicator of breast cancer early detection and screening program 2016-2020

\begin{tabular}{|c|c|c|c|c|c|c|c|}
\hline \multicolumn{2}{|l|}{ Indicators } & $\begin{array}{l}2016 \\
\mathrm{n}(\%)\end{array}$ & $\begin{array}{l}2017 \\
\text { n ( \%) }\end{array}$ & $\begin{array}{l}2018 \\
\text { n (\%) }\end{array}$ & $\begin{array}{l}2019 \\
\text { n (\%) }\end{array}$ & $\begin{array}{l}2020 \\
\text { n (\%) }\end{array}$ & $\begin{array}{l}\text { TOTAL } \\
\text { n \%) }\end{array}$ \\
\hline \multicolumn{2}{|c|}{ Population eligible } & $6,200,200$ & $5,922,390$ & $6,146,136$ & $5,895,595$ & $5,939,400$ & $30,103,721$ \\
\hline \multirow[t]{4}{*}{$\begin{array}{l}\text { Clinical breast } \\
\text { examination }\end{array}$} & $\begin{array}{l}\text { Number of } \\
\text { women }\end{array}$ & 1624600 & 1652347 & 1536534 & 1721514 & 1495007 & $8,030,002$ \\
\hline & $\begin{array}{l}\text { Participation } \\
\text { rate }(\%)\end{array}$ & $25.80 \%$ & $27.90 \%$ & $25.00 \%$ & $29.20 \%$ & $25.10 \%$ & $27.00 \%$ \\
\hline & $\begin{array}{l}\text { Abnormal } \\
\text { finding }\end{array}$ & 3520 & 3765 & 3601 & 3861 & 3719 & 18,466 \\
\hline & $\begin{array}{l}\text { Average rate } \\
\text { of abnormal } \\
\text { finding } \\
\text { annually }\end{array}$ & $0.22 \%$ & $0.23 \%$ & $0.23 \%$ & $0.22 \%$ & $0.25 \%$ & $0.20 \%$ \\
\hline \multirow[t]{5}{*}{ Mammography } & $\begin{array}{l}\text { Total high risk } \\
\text { women } \\
\text { registered }\end{array}$ & 26,494 & 23,631 & 26,430 & 27,533 & 16,140 & 120,228 \\
\hline & $\begin{array}{l}\text { Mammography } \\
\text { done }\end{array}$ & 17,195 & 11,699 & 12,512 & 23,365 & 8,222 & 72,993 \\
\hline & $\begin{array}{l}\text { Mammography } \\
\text { rate }\end{array}$ & $64.90 \%$ & $49.50 \%$ & $47.30 \%$ & $84.80 \%$ & $50.90 \%$ & $61.00 \%$ \\
\hline & $\begin{array}{l}\text { Confirmed } \\
\text { cancer }\end{array}$ & 51 & 115 & 106 & 166 & 96 & 534 \\
\hline & $\begin{array}{l}\text { Average rate } \\
\text { of confirmed } \\
\text { cancer } \\
\text { annually }\end{array}$ & $0.30 \%$ & $0.98 \%$ & $0.85 \%$ & $0.75 \%$ & $1.17 \%$ & $0.70 \%$ \\
\hline
\end{tabular}


Figure 1: Clinical breast examination(CBE) rate by age group, 2016-2020

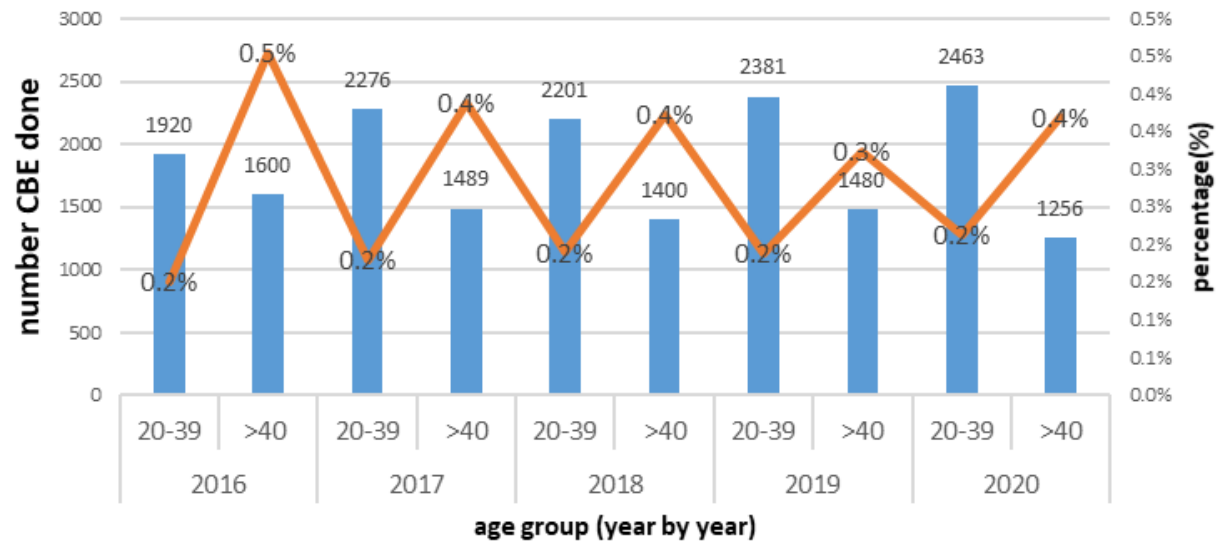

Abnormal finding Percentage

Figure 2 shows the ethnic differences in clinical breast examination uptake. We focused on the major ethnic groups: Malay, Chinese and Indian. Malay women contributed to $64.3 \%$ of the total women who underwent clinical breast examination followed with other ethnicities
(16.5\%) and Chinese (12.5\%). Only $6.7 \%$ of Indian women participated in the program. Data were not available to retrieve for the total number of eligible women in a given ethnicity. Therefore, we are not able to analyze the ethnic-specific participation rate based on the primary ethnicity

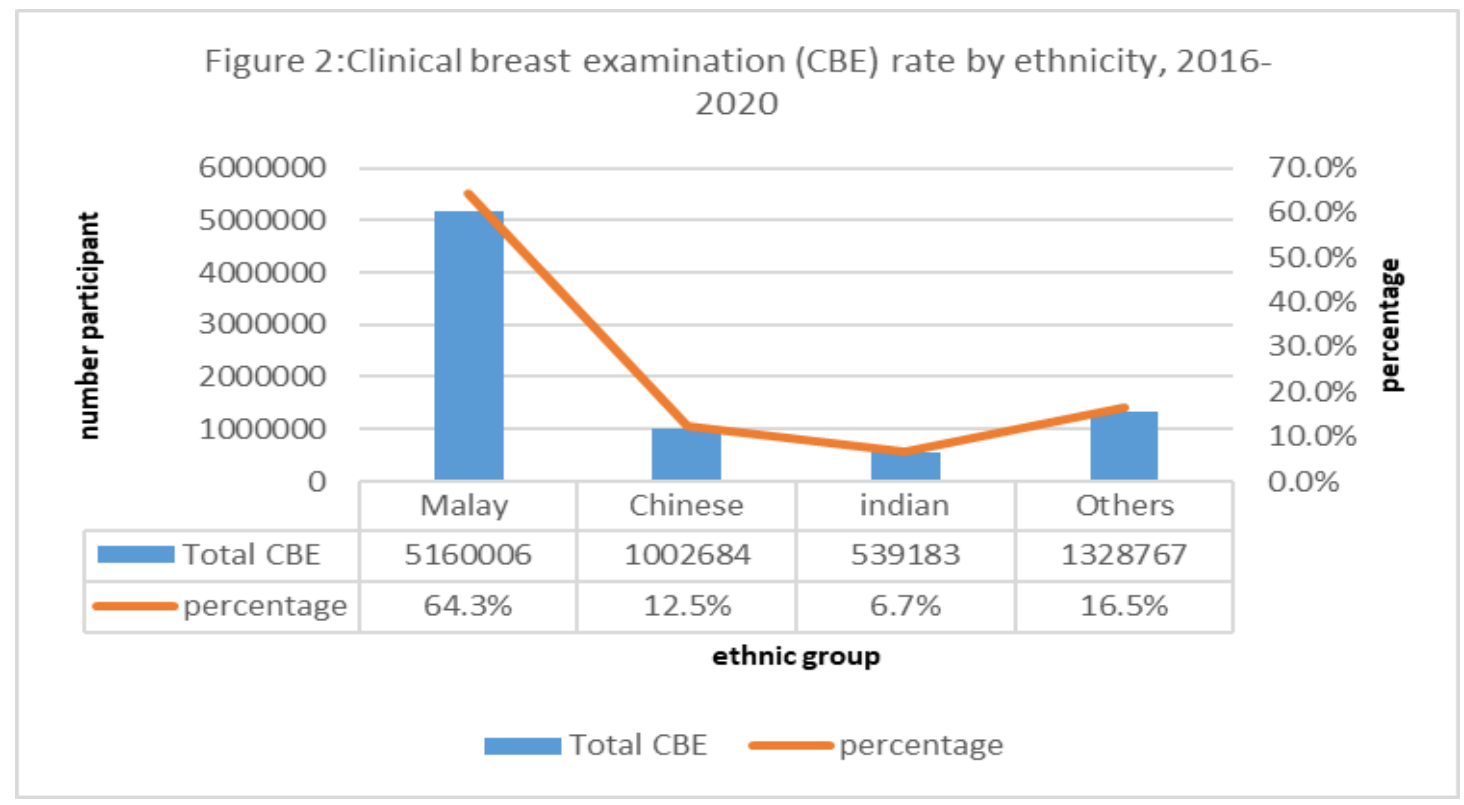

Further analysis of the positivity rate of clinical breast examination in 2016-2020 showed that women 40 years old and above have a higher positivity rate than women under 40 years old (Figure 3). The positivity rate in women aged 40 years and above varied from $0.32 \%$ to $0.45 \%$. All women detected to have abnormal findings will be referred for further assessment and management. The analysis in Figure 4 shows that women aged 30 to 39 years old contributed to $0.01 \%$ to $0.80 \%$ of the mammography screening program in 2016-2020. The majority of the women screened were aged 40-49 years old (39.2\% to $45.0 \%)$. However, women aged 70 years and above contributed to less than $4.0 \%$ of the total screened. 
Figure 3: Positivity rate of clinical breast examination (CBE) by age category, 2016

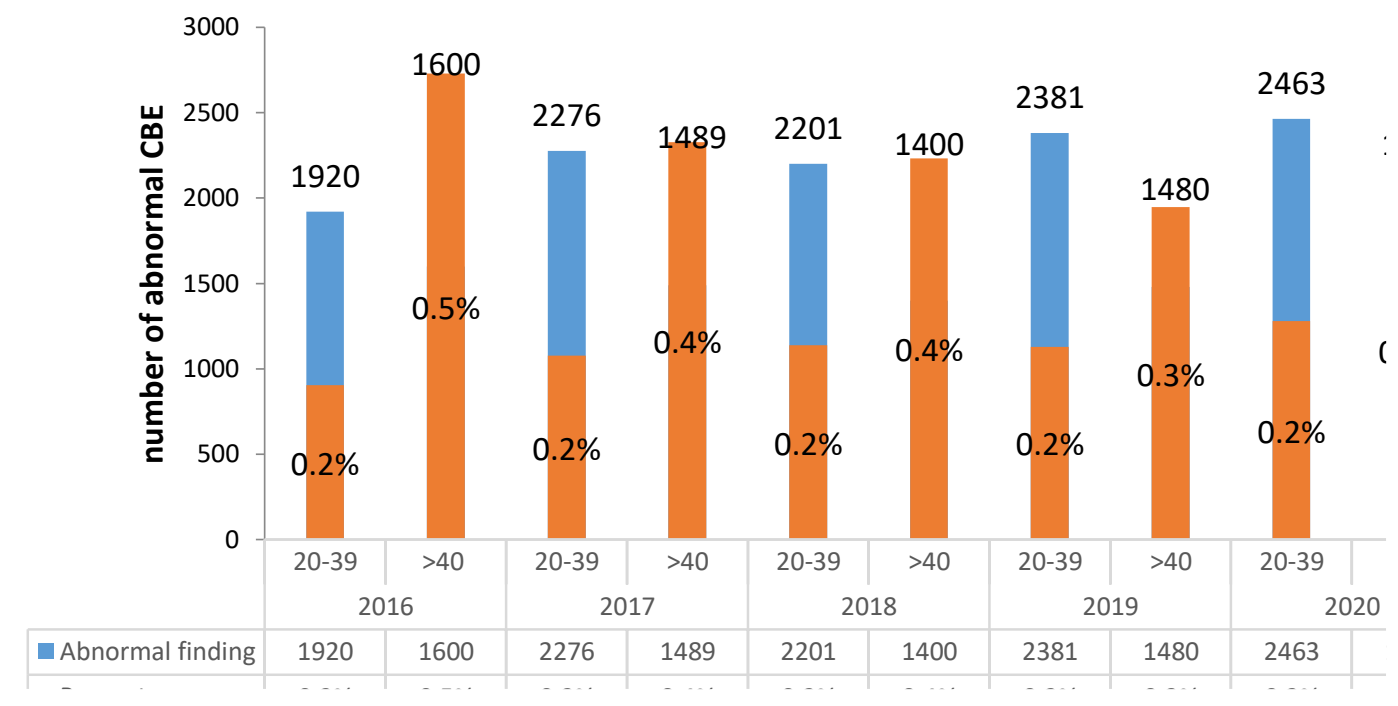

Figure 4: Mammogram (MMG) screening rate by age group, 2016-2020

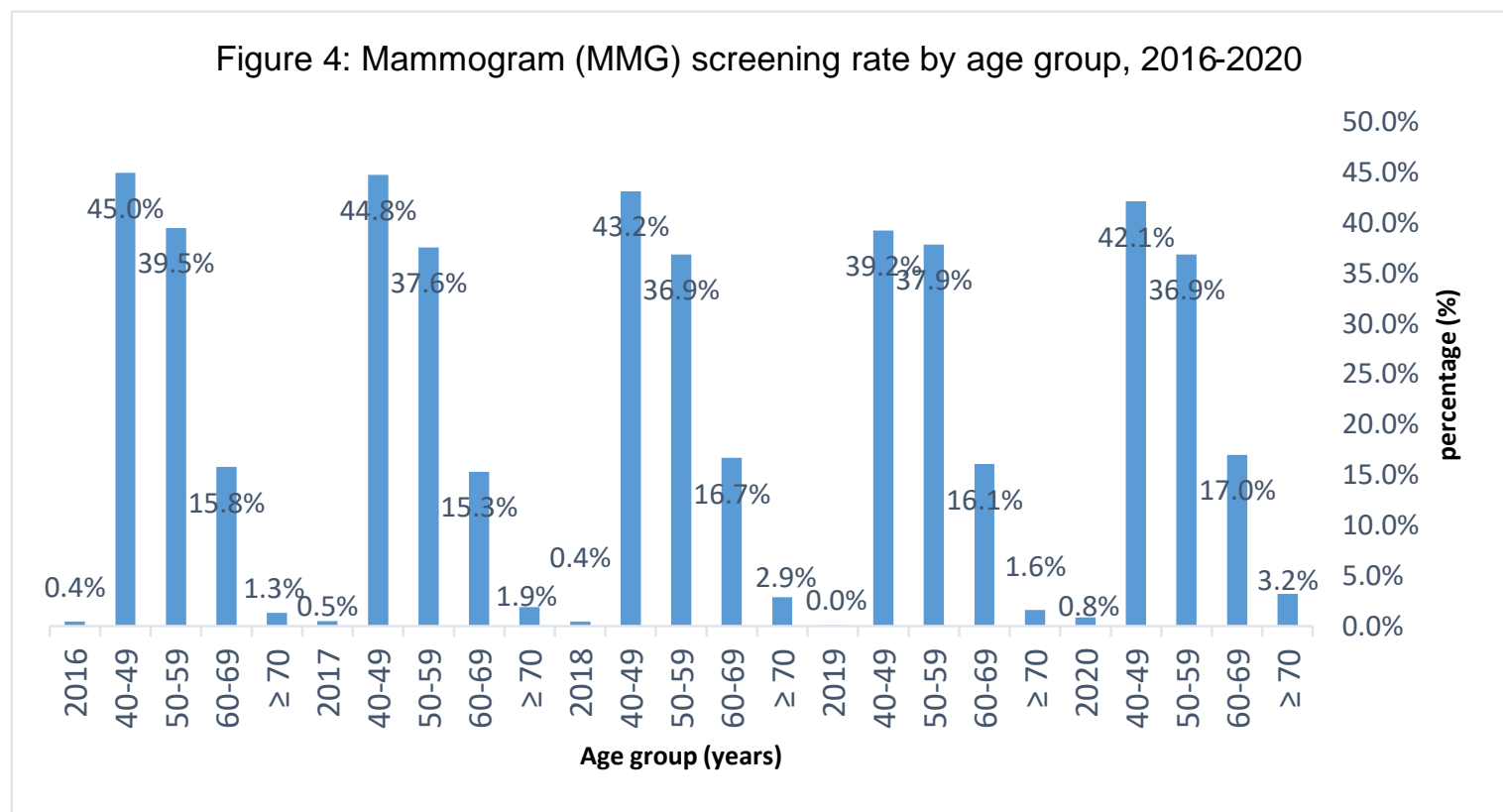

Figure 5 shows the cancer detection rate of the mammogram screening program in 2016-2020. The detection rate varies from $0.3 \%$ to $1.2 \%$, with a mean detection rate of $0.8 \%$. It was highest in 2020, even though the total mammogram performed was lower across the five years. The detailed breakdown of the cancer detection rate by age group (Figure 6) revealed that two groups had the highest detection rate: women aged 70 years and above, followed by women in the younger age group (30-39 years old). Women aged 60-69 years old showed the third highest with the rate of $0.9 \%$. 


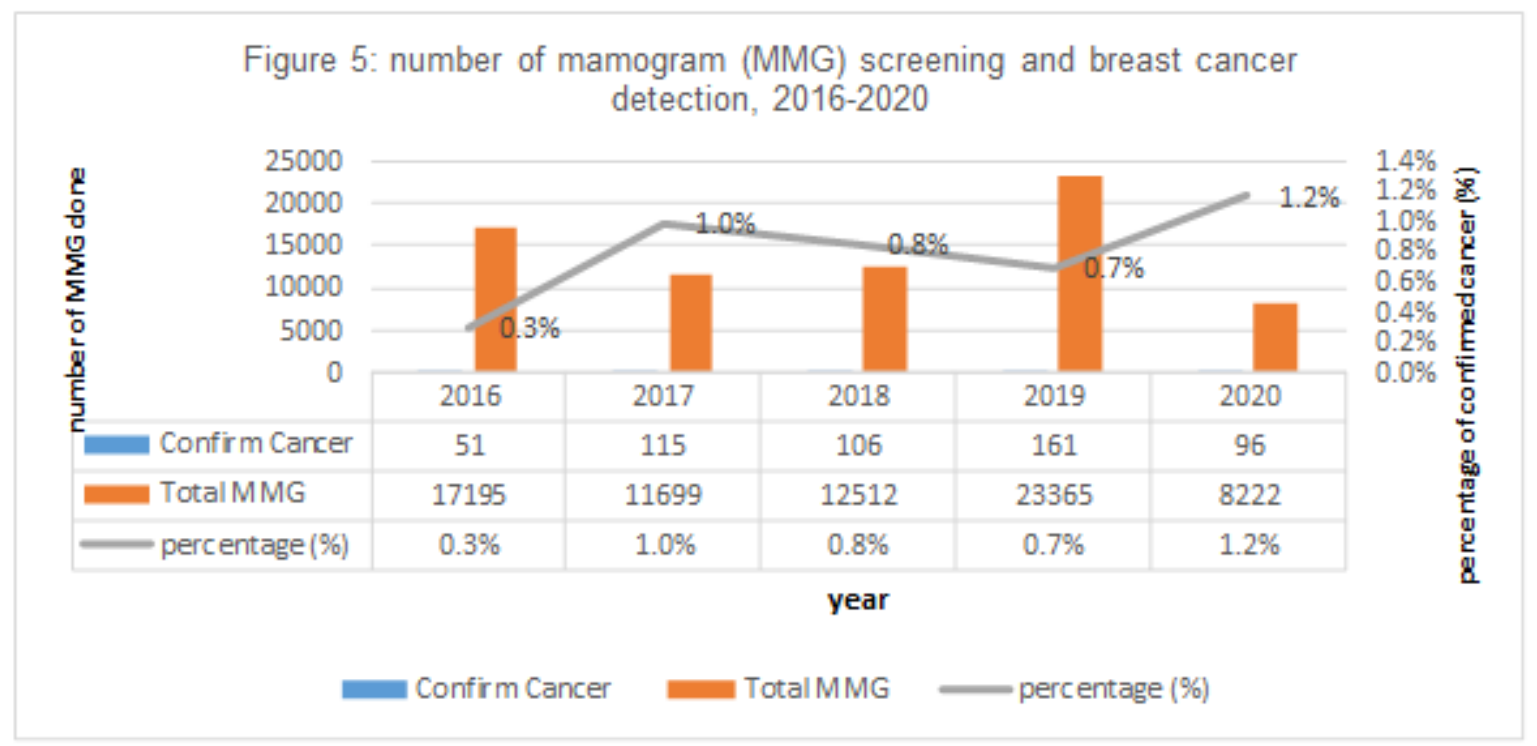

\section{DISCUSSION}

The rate of participation in clinical breast examination among women aged 20 and over has been stagnant over the past five years. The participation rate also reflects coverage for women in the age of between 20 and 60 years old. The main target is to increase participation rate to $27 \%$ at the national coverage and to exceed the target asset (coverage of $25 \%$ of the population). The positive trend that exceeds the target set indicates the heightened awareness and knowledge among women concerning the importance of $\mathrm{CBE}$ in the early identification of breast cancer. In 2007, Thailand had a BSE uptake rate of 40.1 percent ( $18.4 \%$ for monthly BSE), 29.0 percent for CBE, and $5.9 \%$ for mammography ${ }^{19}$. Thailand has a similar policy to Malaysia for breast cancer prevention and control programs.

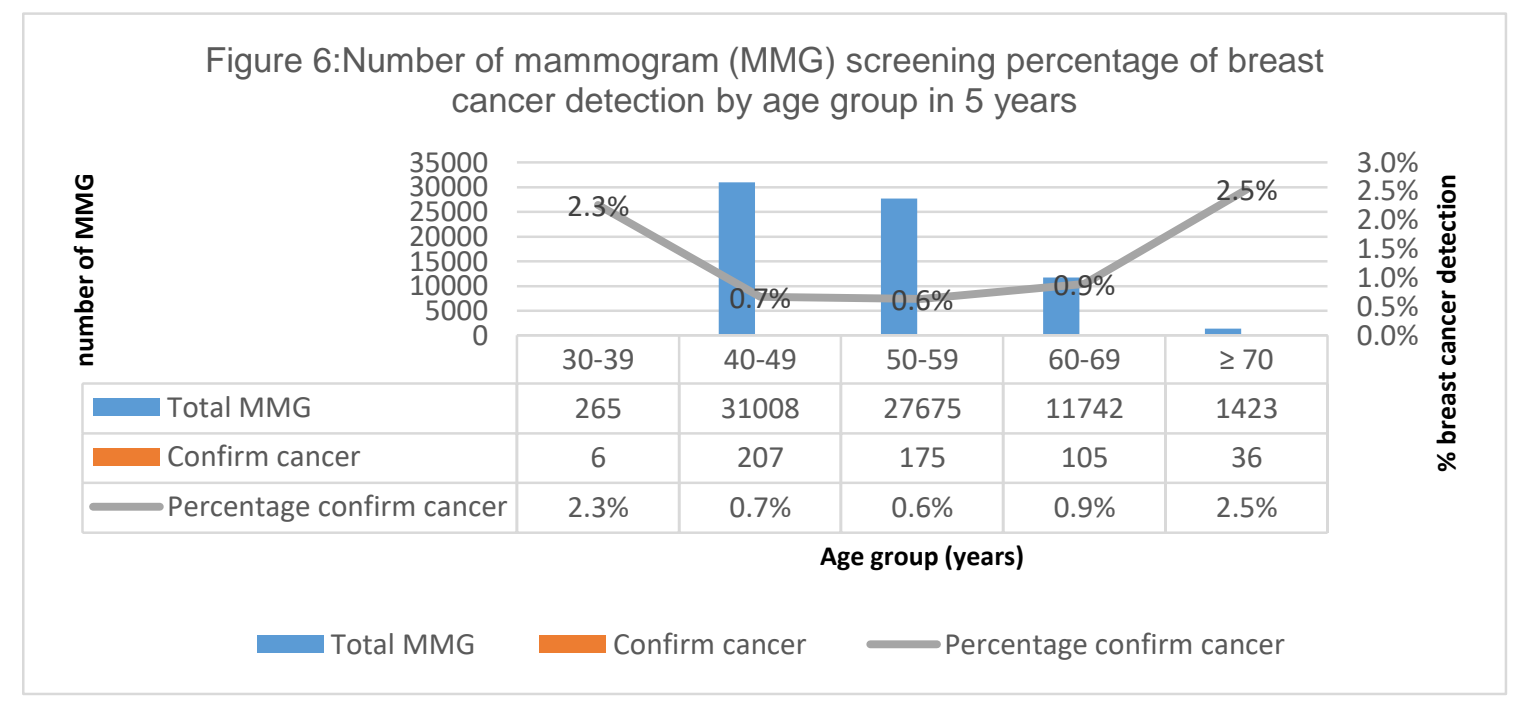

The mammography is offered for breast cancer screening with breast self-examination. However, according to the third National Health Morbidity Survey (NHMS, 2006) study, the highest prevalence rate for BSE was $57.14 \%$, followed by CBE (51.77\%) and only $7.57 \%$ for mammography in $2006^{20}$. The same finding from Norlaili et al. ${ }^{21}$ reported that $60.7 \%$ of rural women in Malaysia practised $\mathrm{BSE}, 56.1 \% \mathrm{CBE}$, and $7 \%$ had undergone mammography screening. We can conclude that the differences in the findings were due to the nature of the methodology and analysis generated. Our study is retrospective in nature, using the existing secondary data of the Ministry of Health facilities from all over the states in Malaysia. The result measured the yearly participation rate as opposed to other studies, mostly measuring the prevalence rate. Even if it is not a prevalence rate, the result is still relevant and may represent the national achievement, especially in a targeted populationbased approach.

Further analysis on the differentiation of the age group and $\mathrm{CBE}$ shows that the highest number of women who underwent $C B E$ were women aged 20 to 39 years old compared to women more than 40 years old. Most of the women were Malay as 
compared to other ethnic groups. Similar findings were found in the third National Health Morbidity Survey (NHMS, 2006), which showed that the prevalence rate for breast examination was high in the 30-34-year-old age group (82.04 per cent $)^{20}$. This age group (20-39 years) is a childbearing age group often treated at the Maternal and Child Health Clinic compared to women in their forties and older.Therefore, they were offered the services during antenatal care for clinical breast examination and later for a mammogram if positive indicative present. However, our study did not determine the proportion of participation of each ethnic group since the data used in the analysis was an aggregated data.

The majority of the women have a normal CBE finding. Only $0.2 \%$ were abnormal during the breast examination and mainly were the older age group (more than 40 years old). However, there was no information on the proportion of those abnormality findings to cancer diagnosis. In the future, there should be a mechanism to incorporate the analysis in the national report. Although the proportion of the abnormality detected is small, it is a valuable technique for detecting early signs of breast cancer. A study by Provencher et al. ${ }^{22}$ found that if CBE had not been performed, a higher number of cancers would have gone undetected. When compared to cancers discovered solely by mammography, CBEdetected malignancies were more aggressive. Mittra et al. ${ }^{14}$ mentioned that CBE is an alternative modality of breast cancer screening. It demonstrates that $\mathrm{CBE}$ screening reduces breast cancer mortality in Indian women aged 50 years old and over while preventing overdiagnosis ${ }^{14}$. The amount of sensitivity of CBE is mainly dependent on the health personnel's expertise and skills. Clinical breast screening is a low-cost procedure that can enhance the detection of breast cancer.Therefore, the health care workers in clinics, particularly those working in maternal and child health clinics, should attend regular refresher courses to ensure that their method is up to date and follows CBE standards. Furthermore, healthcare personnel who do CBE for clients should be monitored regularly. In addition, regular supervision and monitoring should be carried out to ensure that the screening program and quality of data capturing are maintained.

Malaysia lacks a population-based mammography screening program. The number of high-risk women who received mammography screening is directly proportional to the number of women who visit primary care clinics for breast cancer screening and the number of mammogram available. Malaysian mammogram screening participation on average was $61.0 \%$ (range between $47.3 \%$ and $84.5 \%$ ) which is much higher than mammogram screening uptake in Thailand, where there is no population-based screening programme in Thailand and only $5.9 \%$ in 2007 and $10.1 \%$ in $2009^{23}$. In contrast to Singapore, where a population-based screening programme (Breast Screen Singapore, BSS) exists, BSS participation has stayed over $10 \%$ since 2005 . Mammography rates in the United States increased from $29.7 \%$ before the BSS to $39.6 \%$ in 2010 after the BSS $^{24}$. Our findings, however, were limited to women who visited primary care clinics and may not represent the total population.

Mammography was influenced by various factors, including awareness, anxiety and, sociodemographic features. Furthermore, the availability and accessibility of mammography services are critical for ensuring service equity. According to Aidalina et al..$^{25}$, there seemed to be a misdistribution of facilities with the mammogram. Most mammography facilities were concentrated in the Malaysian Peninsula's central and west coast regions, located in the country's major cities. The situation is similar to that of neighbouring countries such as Thailand, where Bangkok has $50.0 \%$ of all mammography facilities, compared to only $5.0 \%$ in the country's northern region. Only about 30 provinces have mammography facilities while the other 46 have none ${ }^{26}$. Therefore, there is a need to pull all the resources. The leading providers such as private hospitals, NGOs, and local health authorities need to map and strategize the services to reach the women needed. Notwithstanding, the hassle such as affordability and accessibility can be tackled through multiple collaborations and good coordination to ensure an effective mode of delivery. This study shows that the detection rate of confirmed cancer was high in two groups: women less than 40 years old and more than 70 years old. This finding is tricky because there has been some dispute about the efficacy of mammography screening in young women.Mammography should be used to screen average-risk women between the ages of 50 and 74 years old, according to most guidelines ${ }^{27}$.

Breast cancer detection rates at mammographic screening were equivalent in women 35-39 and 40-49 years old, according to Liberman et al. ${ }^{28}$. However, the statistics do not rule out a detection rate disparity of more than twice between these groups. If these findings are verified in a more extensive study, the value of mammographic screening in women aged 35 to 39 years old may need to be reconsidered ${ }^{28}$. However, differences in the balance of advantages and disadvantages must be obtained to prevent over-diagnosed and over-treatment of unnecessary reasons. A specific framework for a national screening program that integrates the demands, needs and burden of the diseases should be aligned as mentioned in previous studies 29,30 


\section{CONCLUSION}

Incidence of breast cancer is increasing and becoming priority for women health program manager to evaluate the breast cancer screening program achievement in preventing one of the listed public health problems in Malaysia. Improving early diagnosis is an essential strategy for cancer control in all contexts, including strengthening health systems, providing universal health coverage and women empowerment through awareness campaign. The current policy and strategies should be revised to improve the quality and accessibility of the clinical breast examination and mammography services. Services must be integrated with all screening and intervention programs in primary health clinics, and not just women-centred services coming from maternal and child health services. The success of breast cancer prevention and control programs requires comprehensive planning that engages all stakeholders and emphasis on local needs responsiveness. More importantly is to create good awareness to promote the screening program sustainable and accessible to all women in need. Clinicians and policymakers should remain optimistic that effective, collaborative breast cancer control planning and practical tools used in early detection, diagnosis, and treatment will help patients and their families to have better quality of life. More pilot, research studies, and quality assurance programmes that employ both short- and long-term process metrics can aid in determining the program's future direction.

\section{Limitations of the study}

Analyzing national data to predict program evaluation has always faced a limitation in data completeness if it is not under the policy. However, the datasets analyzed are minimal, making it difficult to determine the gap and the potential improvement of the policy.

\section{Acknowledgement}

We would like to thank the Director-General of Health Malaysia for his permission to publish this article. This is a part of research conducted under UKM grant (FF-2019-371/1) for women health program evaluation and fisibility.

\section{Conflict of interest \\ None}

\section{Source of funding}

This publication supported by the UKM matching grant FF-2019-371/1.

\section{Ethical approval}

None (This is a secondary analysis of our breast cancer-screening program)

\section{References}

1. Parkin DM, Bray F, Ferlay J, Pisani P.
Estimating the world cancer burden: Globocan 2000. Int J Cancer. 2001;94(2):153-6. doi: 10.1002/ijc. 1440. PMID: 11668491.

2. Sung H, Ferlay J, Siegel RL, Laversanne M, Soerjomataram I, Jemal A, et al. Global cancer statistics 2020: GLOBOCAN estimates of incidence and mortality worldwide for 36 cancers in 185 countries. CA Cancer J Clin. 2021 ;caac.21660.

3. Bellanger $M$, Zeinomar $N$, Tehranifar $P$, Terry MB. Are Global Breast Cancer Incidence and Mortality Patterns Related to Country-Specific Economic Development and Prevention Strategies? J Glob Oncol. 2018 ;4:1-16. doi: 10.1200/JGO.17.00207. PMID: 30085889; PMCID: PMC6223528.

4. da Costa Vieira RA, Biller G, Uemura G, Ruiz CA, Curado MP. Breast cancer screening in developing countries. Clinics (Sao Paulo). 2017;72(4):244-253. doi: 10.6061/clinics/2017(04)09. PMID: 28492725 ; PMCID: PMC5401614.

5. National Cancer Institute Ministry of HealthMalaysia. National Cancer Registry Report 2012-2016.June 2019. ISBN: 978967-16142-2-8

6. Norsa'adah B, Rahmah MA, Rampal KG, Knight A. Understanding barriers to Malaysian women with breast cancer seeking help. Asian Pac J Cancer Prev. 2012;13(8):3723-30. doi: 10.7314/apjcp.2012.13.8.3723. PMID: 23098462.U

7. Lauby-Secretan B, Scoccianti C, Loomis D, Benbrahim-Tallaa L, Bouvard V, Bianchini $F$, et al. Breast-Cancer Screening Viewpoint of the IARC Working Group. $N$ Engl J Med. 2015 ;372(24):2353-8. Available from: https://www.nejm.org/doi/full/10.1056/ NEJMsr1504363

8. Bleyer A, Welch HG. Effect of Three Decades of Screening Mammography on Breast-Cancer Incidence. N Engl J Med 2012;367(21):1998-2005.

DOI:10.1056/NEJMoa1206809

9. Pape R, Spuur KM, Umo P. Factors contributing to low participation in mammography screening in Papua New Guinea. Radiography 22(2016) e151-e158. http://dx.doi.org/10.1016/j.radi.2016.04. 012

10. Thomas DB, Gao DL, Ray RM, Wang WW, Allison CJ, Chen FL, Porter P, Hu YW, Zhao GL, Pan LD, Li W, Wu C, Coriaty Z, Evans I, 
Lin MG, Stalsberg H, Self SG. Randomized trial of breast self-examination in Shanghai: final results. J Natl Cancer Inst. 2002;94(19):1445-57. doi: 10.1093/jnci/94.19.1445. PMID: 12359854.

11. Semiglazov VF, Sagaidak VN, Moiseyenko VM, Mikhailov EA. Study of the role of breast self-examination in the reduction of mortality from breast cancer. The Russian Federation/World Health Organization Study. Eur J Cancer. 1993;29A(14):203946. PMID: 8280499.

12. Qaseem A, Lin JS, Mustafa RA, Horwitch CA, Wilt TJ; Clinical Guidelines Committee of the American College of Physicians, Forciea MA, Fitterman $\mathrm{N}$, lorio $\mathrm{A}$, Kansagara D, Maroto M, McLean RM, Tufte JE, Vijan S. Screening for Breast Cancer in Average-Risk Women: A Guidance Statement From the American College of Physicians. Ann Intern Med. 2019;170(8):547-560. doi: 10.7326/M182147. Epub 2019 Apr 9. PMID: 30959525.

13. Monticciolo DL, Newell MS, Hendrick RE, Helvie MA, Moy L, Monsees B, et al. Breast Cancer Screening for Average-Risk Women: Recommendations From the ACR Commission on Breast Imaging. J Am Coll Radiol. 2017;14(9):1137-43.

14. Mittra I, Mishra GA, Dikshit RP, Gupta S, Kulkarni VY, Shaikh HKA, Shastri SS, Hawaldar R, Gupta S, Pramesh CS, Badwe RA. Effect of screening by clinical breast examination on breast cancer incidence and mortality after 20 years: prospective, cluster randomised controlled trial in Mumbai. BMJ. 2021 Feb 24;372:n256. doi: 10.1136/bmj.n256. Erratum in: BMJ. 2021 Mar 19;372:n738. PMID: 33627312; PMCID: PMC7903383.

15. World Health Organization. WHO position paper on mammography screening. ISBN $\begin{array}{lllll}978 & 92 & 4 & 150793 & 63\end{array}$ http: / /apps.who.int/iris/bitstream/handl e/10665/137339/9789241507936_eng.pdf

16. Family Health Development Division. Adult health.

https: / /fh.moh.gov.my/v3/index.php/pag es/public/adult-health

17. Malaysian Health Technology Assessment Section (MaHTAS). Management of Breast Cancer (Third Edition). ISBN: 978-9672173-99-1

http: / /www.moh.gov.myhttp//www.acad med.org.my

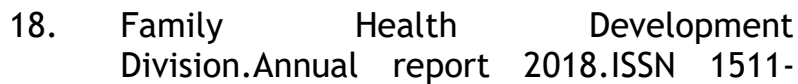

1512.

http: / /fh.moh.gov.my/v3/index.php/com ponent/jdownloads/send/47-bpkk/628annual-report-family-health-developmentdivision-2018? Itemid=0

19. Mukem S, Meng $\mathrm{Q}$, Sriplung $\mathrm{H}$, Tangcharoensathien $\mathrm{V}$. Low coverage and disparities of breast and cervical cancer screening in Thai women: Analysis of national representative household surveys. Asian Pacific $J$ Cancer Prev. 2016;16(18):8541-51.

20. Maznah D, Sofea R, Awang B. Breast Cancer Prevention and Control Programs in Malaysia. Asian Pacific journal of cancer prevention: $2011,12(6): 1631-4$

21. Norlaili AA, Fatihah MA, Daliana NF, Maznah D. Breast cancer awareness of rural women in Malaysia: is it the same as in the cities? Asian Pac J Cancer Prev. 2013;14(12):7161-4. doi: 10.7314/apjcp.2013.14.12.7161. PMID: 24460269.

22. Provencher L, Hogue JC, Desbiens C, Poirier B, Poirier E, Boudreau D, et al. Is clinical breast examination important for breast cancer detection? Curr Oncol 2016;23(4):e332-9. Available from: /pmc/articles/PMC4974039/

23. Mukem S, Sriplung $\mathrm{H}$, McNeil E, Tangcharoensathien V. Breast cancer screening among women in Thailand: analyses of population-based household surveys. J Med Assoc Thai. 2014 ;97(11):1106-18. PMID: 25675674.(

24. Loy EY, Molinar D, Chow KY, Fock C. National Breast Cancer Screening Programme, Singapore: evaluation of participation and performance indicators. J Med Screen. 2015 ;22(4):194-200. doi: 10.1177/0969141315589644. Epub 2015 Jun 16. PMID: 26081449.L

25. Mahmud A, Aljunid SM. Availability and accessibility of subsidized mammogram screening program in peninsular Malaysia: A preliminary study using travel impedance approach. PLOS ONE 2018;13(2): $\quad$ e0191764. https: //doi.org/10.1371/journal.pone.019 1764

26. Mahmud A, Aljunid SM. The uptake of Mammogram screening in Malaysia and its associated factors: A systematic review. Med J Malaysia 2018;73 (4):2018

27. Rahmah MA, Aniza I, Che Engku Nor Bahiyah CE. Do elderly women in Malaysia 
go for mammogram screening? Malaysian Journal of PublicHealth Medicine 2013; 519: 79-6

28. Liberman L, Dershaw DD, Deutch BM, Thaler HT, Lippin BS. Screening mammography: value in women 35-39 years

old. http: / /dx.doi.org/102214/ajr16118517320 ;161(1):53-6.

29. Sutan R. Urbanisation Challenge: Conceptual Framework Alignment in
Family

Health

Improvement- Process Needs. Med J Malaysia 2019; 74 (Supl 2):2019.

30. Sutan R, Siregar PP. Access To Reproductive Health Services Among Migrant Indonesian Female Workers In Peninsular Malaysia. Malaysian Journal of Public Health Medicine, 21(2), 449-456. https://doi.org/10.37268/mjphm/vol.21/ no.2/art.1133 